\section{Relation between Length of Muscle and Breakdown of Phosphorylcreatine in Isometric Tetanic Contractions}

RECENT experiments have shown that adenosine triphosphate (A'TP) is actually utilized by working muscles during single contractions but is normally resynthesized during the contraction by the action of ATP-Cr transphosphorylase and ATP-AMP transphosphorylase (myokinase $)^{1-4}$. A breakdown of phosphorylcreatine (PCr) at $0^{\circ} \mathrm{C}$ during single isotonic contractions has been observed directly in frog rectus abdominis muscles (Rana pipiens) treated with 2,4-dinitrophenol to reduce the high tissue content of this substance. There is a linear relationship between the amount of breakdown and the work performed, with very little $\mathrm{PCr}$ utilized in activation and shortening per se of these muscles. The experiments reported here show that rectus abdominis muscles cleave PCr during short isometric tetanic contractions in amounts proportional to the time and to the developed tension.

Fig. I shows that during the first second of an isometric contraction at rest length the $\mathrm{PCr}$ breakdown at $0^{\circ} \mathrm{C}$ was only $0.19 \pm 0.09 \mu \mathrm{mole} / \mathrm{g}$ muscle, which is about one-fifth the breakdown in $5 \mathrm{sec}$, that is, $0.89 \pm 0.19 \mu \mathrm{mole} / \mathrm{g}$ muscle. Under these conditions the rectus abdominis muscles develop a maximum tension of about $60 \mathrm{~g}$ within 0.5 sec; therefore, the PCr breakdown during the development of tension is not measurably different, within our experimental error, from that during maintenance which requires a steady consumption of energy, for at least the first 5 sec.

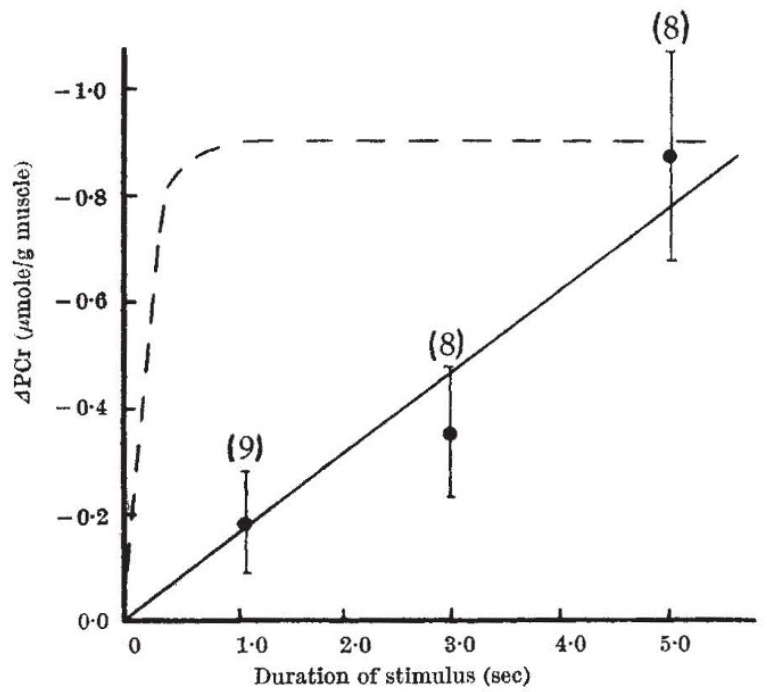

Fig. 1. Relationship of phosphorylcreatine (PCr) breakdown to the duration of stimulation in maintained isometric contractions of frog rectus abdominis muscles at rest length at $0^{\circ} \mathrm{C}$ stimulated by 12 supramaximal electricul pulses per sec. The paired muscles from female Rana pipiens were dissected free, separated, and maintained in oxygenated Ringer's solution at room temperature for about 1-3 h. The isolated muscles were treated with $0.25 \mathrm{mM}$ 2,4-dinitrophenol in Ringer's solution for $40 \mathrm{~min}$ at $20^{\circ} \mathrm{C}$, then mounted between two immobile supports and cooled in a similar solution at $0^{\circ} \mathrm{ClF}$ for 5.0 min. A ${ }^{\circ} \mathrm{Cl}$ muscles were with $0.00125 \mathrm{M}$ EDTA in $48 \mathrm{per}$ cent methanol at $-35^{\circ} \mathrm{C}$ for 7 days. PCr was converted to creatinine by molybdate-catalysed acid hydroPCr was measured with the Jaffé alkaline picrate reaction according to Barker and Ennor (ref. 5). The figures in parentheses refer to the number of muscle pairs used. Means \pm S.E.M. The dashed curve represents the time course of tension development in these muscles. Maximum tension was about $60-65 \mathrm{~g}$ for a muscle weighing about $200 \mathrm{mg}$

Since the tension developed during an isometric contraction depends erucially on the length of the muscle, the relations between PCr breakdown, tension, and muscle length were measured and are shown in Fig. 2. It is interesting that the energy utilization falls almost to zero at long and short lengths where the developed tension is small or zero. Fig. 2 also shows that PCr breakdown and developed tension are related in the same manner to the length.

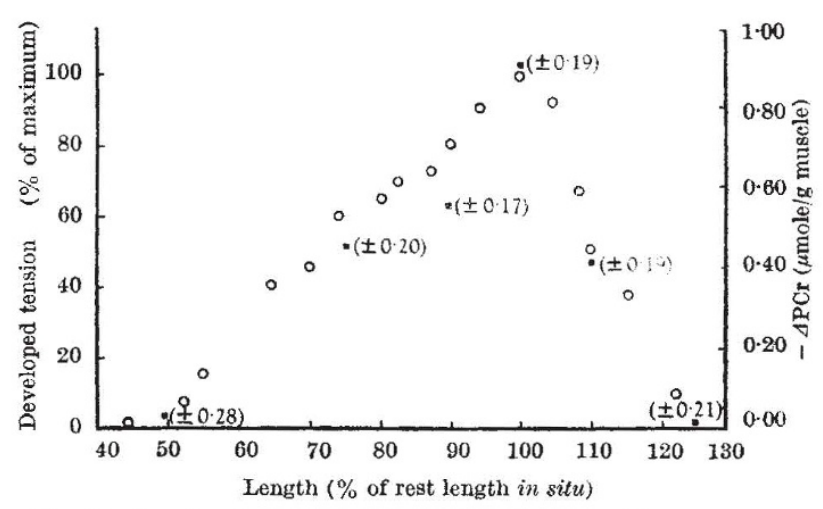

Fig. 2. Developed tension and phosphorylcreatine (PCr) changes in isometric contractions of frog rectus abdominis muscles at differen muscle lengths in a 5-sec tetanus at $0^{\circ} \mathrm{C}$. The muscles were treated as with a Grass FT03 tension transducer coupled to a recorder. O. Tension with a Grass FT03 tension transducer coupled to a recorder. O, Tension developed as a percentage of the maximum tension: each value is for
$2-4$ pairs of muscles; $\mathrm{PCr}$ breakdown $( \pm S . E . M$.$) ; each value is$ for 8-12 pairs of muscles

These results are similar to the finding of Fenn and Latchford ${ }^{6}$ that the heat for maintenance of tonsion in sartorius muscles is less at short and long lengths than at rest length. But they are different from those of Maréchal and Mommaerts ${ }^{7}$, who failed to find an effect of length on maintenance metabolism in experiments on $\mathrm{PCr}$ breakdown in iodoacetate-treated sartorius muscles. Their experiments, however, were not regarded as final.

It seems very unlikely that developed tension is the process leading directly to the utilization of ATP, since experiments in which activated muscles, pre-treated with 1-fluoro-2,4-dinitrobenzene, were forcibly stretched have shown that the breakdown of ATP can be greatly reduced despite a large increase in tension ${ }^{8}$. It thus appears that ATP, and hence PCr, breakdown occurs when the developed tension causes relative inward movements of the actin and myosin filaments, as in isotonic contraction. This cannot occur in isometric contractions of greatly pre. stretched or pre-shortened muscles, which either cannot develop tension or cannot shorten further. The relatively large breakdown of $\mathrm{PCr}$ near rest length in these muscles, during isometric contractions, is probably a manifestation of continuous internal work as suggested by Fenn and Latehford ${ }^{6}$. This could follow from small instantaneous differences in the number of cross links formed, and hences the tension developed, between individual myosin and actin filaments. Since the overall length of these muscles was fixed, this would result in a continuous series of rapid. ultra-micro to-and-fro movements of these filaments which would result in the dissipation of work as frictional heat.

This work was supported in part by U.S. Public Health Service grant $H E-02520$ and $G P M-12921$.

\section{A. A. INFANTE* Dzintra KlauptKs \\ R. E. Davies}

Laboratories of Biochemistry,

Department of Animal Biology,

School of Veterinary Medicine.

University of Pennsylvania, Philadelphia.

* Pre-doctoral Fellow of the U.S. National Institutes of Health.

${ }^{\prime}$ Cain, D. F., and Davies, R. E., Biochem. Biophys. Res. Comm., 8, 361 (1962).

${ }^{2}$ Cain, D. F., Infante, A. A., and Davies, R. E., Nature, 196, 214 (1962).

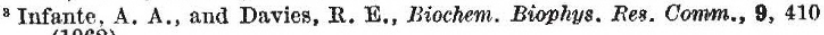
(1962).

4 Infante, A. A., Ph.D. thesis, Univ. Pennsylvania (1963).

Barker, H., and Ennor, A. H., Biochim. Biophys. Acta, 7, 272 (1951).

- Fenn, W. O., and Latchford, w. B., J. Physiol., 80, 213 (1933).

'Maréchal, G., and Mommaerts, W. F. H. M., Biochim. Biophys. Acta, 70. 53 (1963).

"Infante, A. A., Klaupiks, D., and Davies, R. E., Science (submitted for publication). 